\title{
Sharenting... ¿la vida de los niños debe ser compartida en las redes sociales?
}

Sharenting... should children's lives be disclosed on social media?

El uso de las redes sociales ha explotado a nivel global y muchas personas comparten hechos de su vida cotidiana en estos entornos en la forma de comentarios, fotos y videos. Facebook, Twitter e Instagram, entre otras que siguen apareciendo, hasta hace 10 años, no existían y hoy son de uso masivo por personas de todas las edades.

Esta incorporación a la vida personal hace que, a menudo, los padres creen las primeras "huellas digitales" de sus hijos desde antes de su nacimiento, cuando comparten imágenes del embarazo. ${ }^{1}$

Por ejemplo, en Estados Unidos, el 92\% de los niños menores 2 años tienen algún tipo de presencia en las redes sociales, y un tercio debutan con su "primera publicación" antes del primer día de vida. ${ }^{2}$

Esta situación puede ser comprensible, ya que el deseo es compartir con familiares, amigos y conocidos las imágenes de sus hijos, que se hace mucho más fácil por un medio de difusión ampliamente adoptado. Otra circunstancia en la cual los padres deciden compartir información sobre sus hijos en las redes sociales es cuando estos niños padecen enfermedades crónicas o huérfanas, pues las redes son un medio para compartir experiencias. ${ }^{3}$

Este fenómeno ha sido identificado como sharenting: se unen las palabras share (compartir) y parenting (crianza) y se define como la práctica de un padre/madre que regularmente usa las redes sociales para publicar y comunicar información detallada sobre su hijo/a. ${ }^{4}$

Pero no se tiene en cuenta que la masividad hace que estas imágenes y comentarios puedan, eventualmente, ser vistas por cualquiera. Es importante conocer dónde está el límite, cuánto y qué se debe compartir.

Los padres deben conocer que existen riesgos en el hecho de compartir información sobre sus hijos en las redes sociales. Entre los daños que pueden suceder, se encuentra el robo de identidad y que se compartan imágenes en sitios que fomentan la pedofilia.

Otro tema para evaluar es el tipo de información que se sube, ya que compartirla puede ser considerado gracioso, pero también la información puede ser vergonzosa y puede ser mal utilizada por otros. ${ }^{5}$

Es importante recordar que la privacidad es un derecho de los niños, así como su identidad en línea, que, a medida que crezcan, la irán armando $\mathrm{y}$, por lo tanto, debe ser definida por ellos y no por sus padres.

En la consulta con el pediatra, a medida que ha aumentado el uso de Internet por parte de los niños, se ha dirigido la atención a las formas en que ellos utilizan las tecnologías digitales.-8

Sin embargo, hasta ahora, no se ha trabajado en los detalles de su información personal que se encuentran disponibles en la Web, ${ }^{9}$ por lo que se debe incorporar como tema por tratar en la consulta y presentarles a los padres/cuidadores el potencial conflicto que existe entre la libertad de los padres de publicar y el derecho del niño a su privacidad.

Por ello, se debe aconsejar a las familias sobre estos temas, ya que los padres pueden no tomar en cuenta que, al utilizar las redes sociales, pueden afectar el bienestar de sus hijos.

Una frase que siempre resume cómo manejarse ante estas situaciones es que no se debe compartir en línea lo que no se compartiría públicamente.

Se ha publicado una serie de recomendaciones que el pediatra puede brindar a los padres / cuidadores de sus pacientes para ayudarlos en el manejo adecuado de la información que expongan en las redes sociales: ${ }^{10}$

1. Se deben familiarizar con las políticas de privacidad de los sitios en los que compartan información.

2. Se deben configurar las notificaciones para que alerten cuando el nombre de su hijo aparezca en los motores de búsqueda (ej.: alertas de Google).

3. Los padres que decidan compartir información sobre problemas de salud o condiciones clínicas de sus hijos deben considerar optar por hacerlo en forma anónima.

4. Se debe tener precaución al compartir la ubicación real del niño o su nombre completo.

5. Se debe otorgar el "poder de veto" a los hijos mayores sobre las publicaciones en línea.

6. No se deben publicar fotos que muestren al 
niño/a en cualquier estado de desnudez.

7. Se debe considerar el efecto que el hecho de compartir información puede tener sobre el estado actual y futuro del niño/a.

No hay que olvidar que cuidar la información sobre los niños que está disponible en la Web es también una forma de cuidarlos para que crezcan sanos.

Dra. Paula Otero
Subcomisión de Tecnologías de Información y
Comunicación
Sociedad Argentina de Pediatría

http: / / dx.doi.org/10.5546/ aap.2017.412

Texto completo en inglés:

http: / / dx.doi.org/10.5546/ aap.2017.eng.412

Cómo citar: Otero P. Sharenting ... ¿la vida de los niños debe ser compartida en las redes sociales? Arch Argent Pediatr 2017;115(5): 412-413.

\section{REFERENCIAS}

1. Ammari T, Kumar P, Lampe C, et al. Managing children's onlineidentities: How parents decide what to disclose about their children online. Proceedings of the 33rd Annual ACM Conference on Human Factors in Computing Systems; 2015: ACM. [Acceso: 19 de mayo de 2017]. Disponible en: http: / / yardi.people.si.umich.edu/pubs / Schoenebeck_ ManagingChildrensIdentities15.pdf

2. Duggan M, Lenhart A, Lampe C, et al. Parents and Social Media.Pew Research Center. Internet \& Technology; 2015. [Acceso: 19 de mayo de 2017].Disponible en: http:/ / www. pewinternet.org/2015/07/16/parents-and-social-media/.

3. Jacobs R, Boyd L, Brennan K, et al. The importance of social media for patients and families affected by congenital anomalies: A Facebook cross-sectional analysis and user survey. J Pediatr Surg 2016;51(11):1766-71.

4. Blum-Ross A, Livingstone S. Sharenting, parent blogging, and the boundaries of the digital self. Popular Communication 2017;15(2):110-25.

5. American Academy of Pediatrics. Researchers Caution About Potential Harms of Parents' Online Posts about Children.2016. [Acceso: 15 de mayo de 2017]. Disponible en:http: / / www.aap.org/en-us/about-the-aap/aap-pressroom/pages/researchers-caution-about-potential-harmsof-parents-online-posts-about-children.aspx.

6. Grupo de Trabajo de Informática. Los pediatras, los padres, los niños e Internet.Sociedad Argentina de Pediatría. [Consulta: 15 de mayo de 2017]. Disponible en: http:/ / www.sap.org.ar/docs/ninos internet.pdf.

7. Holloway D, Green L, Livingstone S. Zero to eight. Young children and their internet use. London: EU Kids Online; 2013. [Acceso: 19 de mayo de 2017]. Disponible en: http: / / eprints.lse.ac.uk/52630/1/Zero_to_eight.pdf

8. Council On Communications and Media. Media Use in School-Aged Children and Adolescents. Pediatrics 2016;138(5):e20162592.

9. Lupton D, Williamson B. The datafied child: The dataveillance of children and implications for their rights. New Media Society 2017;19(5):780-94.

10. Keith BE,Steinberg S. ParentalSharing on the Internet: Child Privacy in the Age of Social Media and the Pediatrician's Role. JAMA Pediatr 2017;171(5):413-4.

\section{La lactancia como diálogo biológico Breastfeeding as a biological dialogue}

Mientras redactábamos el primer artículo para la Serie 2016 sobre Lactancia Materna de Lancet, mi colega, el pediatra británico Simon Murch, propuso una afirmación extraordinaria: "la leche materna es el máximo medicamento personalizado". ${ }^{1}$ Desde entonces, me refiero a la interacción materno infantil durante el amamantamiento como un "diálogo biológico", en el cual el lactante transmite información a la madre sobre sus necesidades y esta responde alterando la cantidad y la composición de la leche. Este intercambio de información implica múltiples mecanismos, pero apenas estamos arañando la superficie de la biología de la lactancia. El artículo de Pannaraj y colaboradores publicado en JAMA Pediatrics ${ }^{2}$ llena un vacío en la bibliografía sobre el tema; en él se cuantifica de qué manera las bacterias presentes en la leche materna y en la piel de la areola contribuyen al desarrollo de la microbiota del lactante y cómo esta es específica de las comunidades microbianas de la madre en comparación con la de otras mujeres lactantes.

Desde hace bastante tiempo, se conocen las propiedades antiinfecciosas de la leche materna: la lactoferrina, las lisozimas, los anticuerpos y los oligosacáridos son solo algunos de los componentes que ayudan a prevenir y luchar contra las infecciones en los lactantes. Los estudios recientes demuestran la presencia de micro ARN, células progenitoras, cortisol y decenas de otras vías biológicas activas. ${ }^{1}$ Si estos compuestos y células se encuentran en la leche materna, deben tener una 